\title{
Early infantile epileptic encephalopathy
}

INSERM

\section{Source}

INSERM. (1999). Orphanet: an online rare disease and orphan drug data base. Early infantile epileptic encephalopathy. ORPHA:1934

Early infantile epileptic encephalopathy (EIEE), or Ohtahara syndrome, is one of the most severe forms of age-related epileptic encephalopathies, characterized by the onset of tonic spasms within the first 3 months of life that can be generalized or lateralized, independent of the sleep cycle and that can occur hundreds of times per day, leading to psychomotor impairment and death. 